\title{
Management of Positive Cervical Lymph Nodes in Parotid Cancer
}

\author{
Ali Zedan ${ }^{1 *}$ Aieat Morsy' ${ }^{2}$, Osama Mustafa ${ }^{3}$, Marwa Hussien ${ }^{4}$ and Ebrahim Aboeleuien ${ }^{1}$ \\ ${ }^{1}$ Department of Surgical oncology, South Egypt Cancer Institute, Assuit University, Egypt \\ ${ }^{2}$ Department of clinical oncology, Assuit University, Egypt \\ ${ }^{3}$ Department of Radiation oncology, South Egypt Cancer Institute, Assuit University, Egypt \\ ${ }^{4}$ Department of Pathology South Egypt Cancer Institute, Assuit University, Egypt
}

Submission: January 25, 2021; Published: February 03, 2021

*Corresponding author: Dr. Ali Zedan, Department of Surgical oncology, South Egypt Cancer Institute, Assuit University, Assuit, Egypt

\begin{abstract}
Objective: Assessment the management of positive cervical lymph nodes in parotid cancer. Associated clinical symptoms, histological types, regional lymph node stage (n stage), occult metastasis, neck dissection by level, recurrence, neck irradiation.

Methods. We carried out a retrospective analysis of 43 patient's pathological positive lymph nodes metastatic from parodied cancer, who underwent neck dissection. treated in years 2010-2020, we analyzed the following parameters: age, sex, pT-Status, tumour size, skin invasion, facial nerve palsy, tumour fixation, extraparotid extension, localization, grade, histology, Distribution of T classification was: T3 (60\%), and T4 $(40 \%)$.

Results: Mean patient age was 52 years, the most common location of cervical Nodes Met. was level II (72\%), then III (49\%) then I (42\%), then IV (40\%) and V (19\%). The incidence was highest among patients with (27.9\%) mucoepidermoid carcinoma was most common, followed by (14.6\%) carcinoma ex-pleomorphic adenoma (9.3\%) with acinic cell carcinoma (7\%) with squamous cell carcinoma, (11.6\%) with adenoid cystic carcinoma, (7.0\%) with adenocarcinoma, (7.4\%) salivary duct carcinoma, When classified by histological grade, 35\% of patients with low/ intermediate-grade versus 65.0\% high-grade ., Pre-operative fine needle aspiration (83.7\%) patients, Post-surgical irradiation was performed in all 43 patients (100\%). The resection status (R) was Negative margins R0. (93\%), lymphovascular space invasion (44.2\%) and (25.6\%) had perineural invasion. Skin invasion in (14\%) patients, and (4.7\%) had regional nodal recurrence (7\%) patients with pN1, vs (93\%) patients with pN2. Pathologically positive lymph node 4 (range: 1-8 Nodes) lymph nodes harvest 29(range, 23-41 lymph nodes).,
\end{abstract}

Conclusion: modified Radical Neck Dissection with additional radiotherapy should be carried out in patients. Nodes positive parotied cancer especially High histological stage, advanced stage, perineural invasion, positive operative edge, a fixed mass with extra parotid extension facial-nerve paralysis and tumor pain in partied cancer.

Keywords: Cervical neck dissection; Histological grade; Lymph node metastases; Parotid carcinoma

\section{Introduction}

Primary parotid carcinoma (PPC) is a comparatively rare ( $0.3 \%$ of all malignancy), [1] and histologically diverse disease [2]. Therefore, data on this neoplasm are usually based on reports pertaining to groups of patients from single institutions, amounting to approximately 100 cases over many years [3]. This is also associated with the problem of metastases to cervical lymph nodes, whose presence significantly increases the risk of locoregional relapse and death, worsening 5- and 10-year
OS and DFS by approximately 50\% [4]. Metastases in N0 nodes (occult) constitute an exceptional problem [5]. This is because in many cases resigning from elective neck dissection (END) in fear of overtreatment can decrease the chances for recovery [6]. Evaluation of actual prevalence and location of occult metastases in PPC based in the literature is made difficult [7]. due to frequent presentation of all major salivary gland tumors and mixing intra/ peri parotid metastases with neck metastases [8]. Accordingly, the 


\section{Cancer Therapy \& Oncology International Journal}

authors analyzed their own material and data from the worldwide literature to identify the probability and probable locations of cervical occult lymph node metastases in PPC $[9,10]$. So, this study aimed to determine how to treatment of positive cervical lymph nodes in parotid cancer.

\section{Patients and Methods}

In years 2010-2020, in the Surgical oncology south Egypt cancer institute, Assuit University, there were 43 patients treated because of primary parotid gland carcinoma contained cervical nodal disease (excluding intra parotied). Surgical, medical records of the patients diagnosed with primary PGC were retrospectively appeared, including age, sex, T stage, neck stage, postoperative pathological report, operation record, adjuvant treatment, and follow-up information, Tumors size, age, gender, clinical features (mobility, pain, facial-nerve palsy), (Figures $1 \& 2$ ) histological type grades. Sites of lymph node metastasis, resection margins, skin involvement, (Figure 3). tumor-grade, perineural or lymph vascular invasion, extra glandular extension, Neck Recurrence (Figure 4). postoperative radiotherapy was extracted and analyzed, we excluded patients with (i.e., lymphomas, sarcomas), patients with metastatic disease to the parotid (e.g., from skin carcinomas).

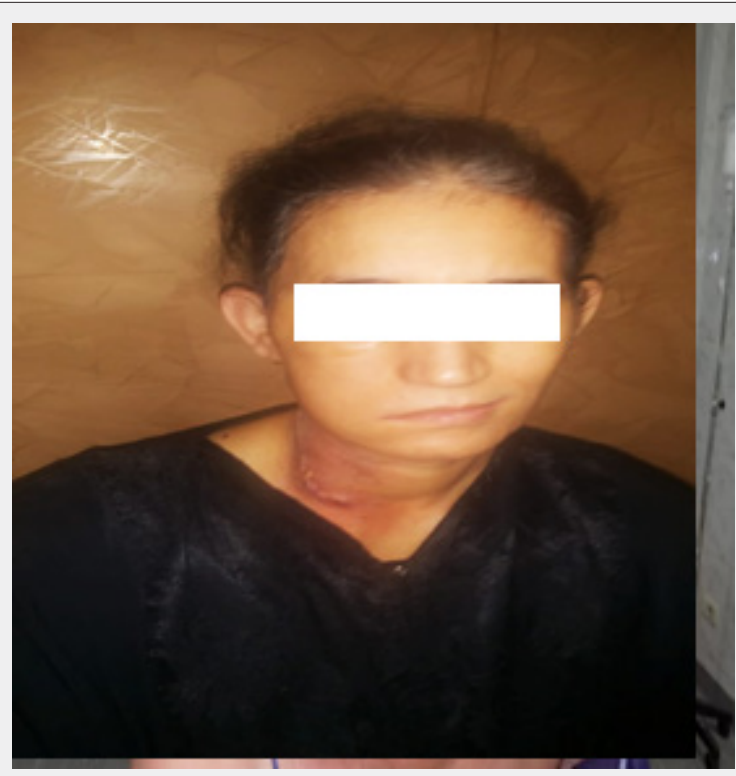

Figure 1: fascial palsy Right modified Radical Neck Dissection, Total Radical parotidectomy.

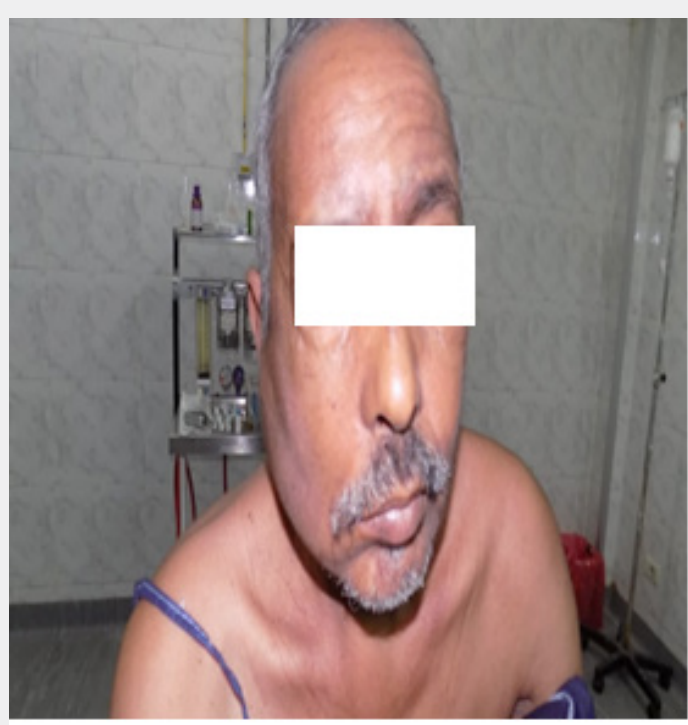

Figure 2: Preoperative fascial palsy Right Parotied Cancer. 


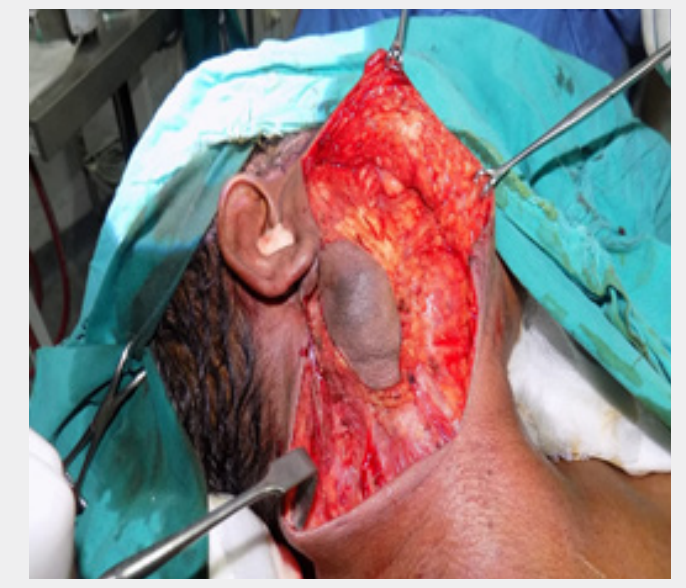

Figure 3: Skin invasion in Right Parotied Cancer.

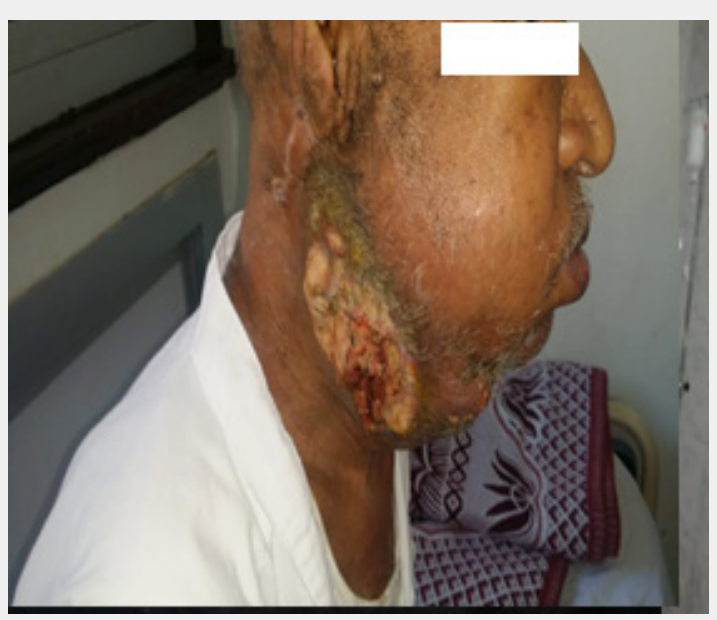

Figure 4: Recurrent Neck Tumor After Total Parotidectomy modified Radical Neck Dissection.

This study was approved by all relevant institutional review boards before the collection of patient information. Diagnostic Work-Up Preoperative staging of the neck was done by physical examination and ultrasound (US chest radiography. and/or computerized tomography (CT), (Figure 5) and/or magnetic resonance imaging (MRI) and/or positron emission tomography (PET); and/or ultrasound-guided fine needle aspiration cytology., Open biopsy was performed in some patients (Figure 6). For patients in the CNO stage, lymph node dissection can be performed according to the intra-operative pathological examination. Performing a neck dissection in cases of a clinically or radiologically determined presence of lymph node metastases, and/or Frozen section (FS), In 43 patients, modified radical neck dissection (MRND) (levels I-V) was performed (Figures 7-10) ipsilateral neck dissection for 42 and only one patient Bilateral because MRI Revealed contralateral neck involvement by final Pathology the contrayerva node negative. Nodal levels had always been divided into separate levels in the operating theater before they were sent to the histopathology department to minimize labeling and orientation errors of the specimens. (Figure 11) Postoperative scar was completely hidden behind the auricle and hair, (Figure 12), Postoperative radiation therapy were performed in all cases, PORT was recommended 3-6 weeks after surgery. The radiation dose was as follows: radiotherapy of the parotid gland region was performed at 1.8-2.0 Gy five times a week with a total dose of 40-65 Gy, and radiotherapy of the neck at 1.8-2.0 Gy five times a week with a total dose of 40-56 Gy. RT was well tolerated by almost all patients.

Follow-up was performed by means of clinical examination, ultrasound, or MRI at regular intervals ( 6 weeks after surgery and every 3 months thereafter for the first 2 years, every 6 months for the next 3 years, and once a year 5 years after surgery). some Patients had neck and chest CT imaging, and 18-Fluorodeoxyglucose positron emission tomography (FDG-PET), The median follow-up duration was 39 months. 


\section{Cancer Therapy \& Oncology International Journal}

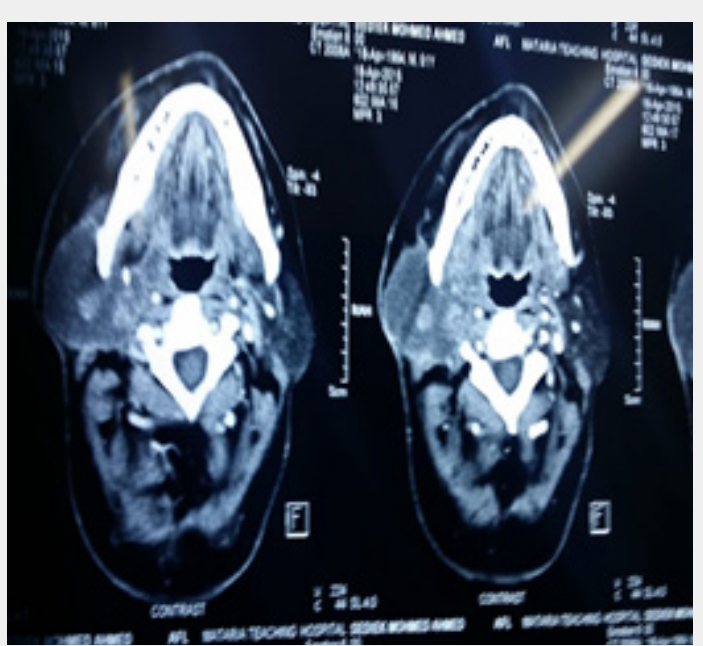

Figure 5: CT Neck malignant parotied with cervical Nodes.

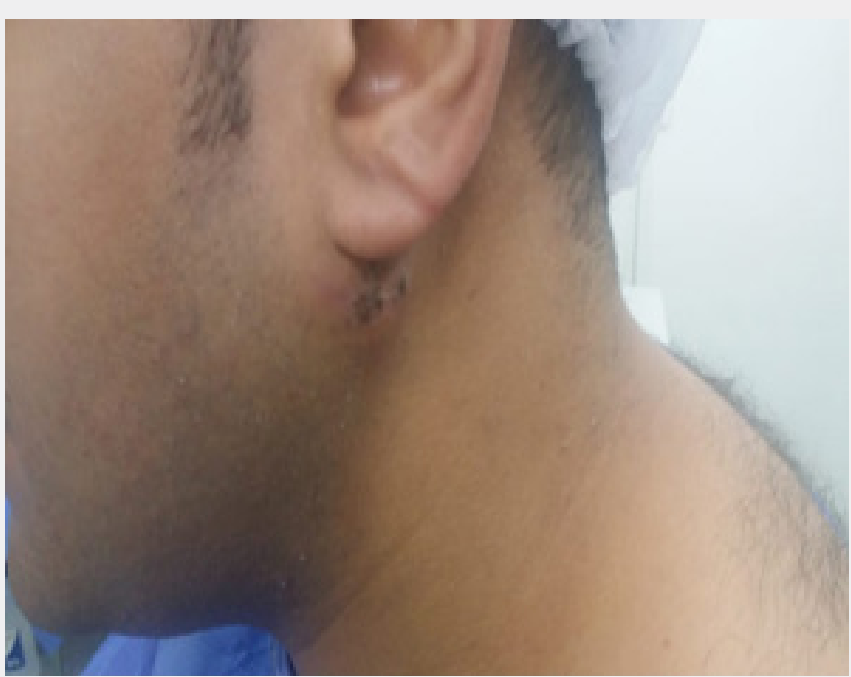

Figure 6: Preoperative open Biopsy in malignant left parotied.

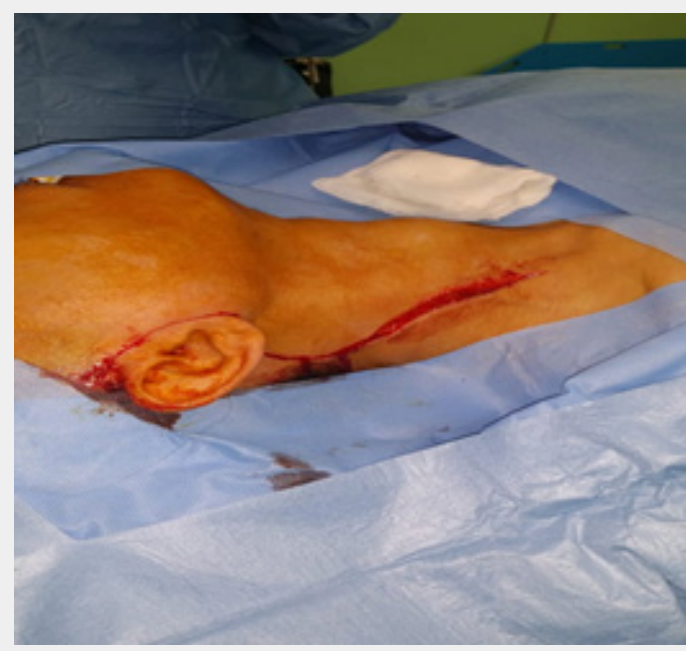

Figure 7: Incision for Total Radical parotidectomy and Right modified Neck Dissection. 


\section{Cancer Therapy \& Oncology International Journal}

Statistical methods: SPSS version 23.0 was used for data management and analysis. Mean and standard deviation described quantitative data \& number and \% described qualitative data.

\section{Results}

Demographics and Clinicopathologic Data. A total number of 43 patients ( 16 female and 27 male) with a mean age of 52 (zone: 29-67 years were ultimately registering. primary tumor location. whole gland was infiltrate in $17(39.5 \%)$ cases; superficial lobe was infiltrate in $26(60.5 \%)$ cases, 12 (27.9\%) patients with pain, tumor was mobile in 29 (67.4\%) patients, Preoperative facial nerve palsy 4 (9.3\%) patients, 34 (79.1) patients had clinical nodal disease while $9(20.9 \%)$ patients Occult metastasis. Extra-parotid extension in $14(32.6 \%)$ patients, Primary tumor size varied < $4 \mathrm{~cm}$ in $22(51.2 \%), \geq 4 \mathrm{~cm}$ in $21(48.8 \%)$ patients, in (Table 1$)$.

Table 1: Clinicopathologic characteristic of 43 patients with parotid gland tumors.

\begin{tabular}{|c|c|c|c|}
\hline & & Mean \pm SD & Median (range) \\
\hline \multicolumn{2}{|c|}{ Age/ age } & $50.95 \pm 10.31$ & $52(29-67)$ \\
\hline & & Count & $\%$ \\
\hline \multirow[t]{3}{*}{ Sex } & Female & 16 & 37.2 \\
\hline & Male & 27 & 62.8 \\
\hline & Total & 43 & 100.0 \\
\hline \multirow{3}{*}{ Localization } & whole gland & 17 & 39.5 \\
\hline & superficial lobe & 26 & 60.5 \\
\hline & Total & 43 & 100.0 \\
\hline \multirow{3}{*}{ Pain } & No & 31 & 72.1 \\
\hline & Yes & 12 & 27.9 \\
\hline & Total & 43 & 100.0 \\
\hline \multirow{3}{*}{ Mobile tumor } & No & 14 & 32.6 \\
\hline & Yes & 29 & 67.4 \\
\hline & Total & 43 & 100.0 \\
\hline \multirow{3}{*}{ Facial-nerve palsy } & No & 39 & 90.7 \\
\hline & Yes & 4 & 9.3 \\
\hline & Total & 43 & 100.0 \\
\hline \multirow{3}{*}{ Occult metastasis. } & No & 34 & 79.1 \\
\hline & Yes & 9 & 20.9 \\
\hline & Total & 43 & 100.0 \\
\hline \multirow{3}{*}{ Extra-parotid extension } & No & 29 & 67.4 \\
\hline & Yes & 14 & 32.6 \\
\hline & Total & 43 & 100.0 \\
\hline \multirow{3}{*}{ Tumor size } & $<4 \mathrm{~cm}$ & 22 & 51.2 \\
\hline & $\geq 4 \mathrm{~cm}$ & 21 & 48.8 \\
\hline & Total & 43 & 100.0 \\
\hline
\end{tabular}

Locally-advanced disease $\mathrm{T}$ stages were distributed as follows: (T3 or T4); T3-26(60.5\%), and T4-17(39.5\%) patients , The pathological grade distribution :High-grade cancer was noted in $28(65.1 \%)$ cases; intermediate / low-grade cancer was noted in 15 (34.9\%) cases, Pre-operative fine needle aspiration 36(83.7\%) patients, Post-surgical irradiation was performed in all 43 patients $(100 \%)$, The resection status (R) was Negative margins R0 were achieved in 49 patients.(93\%) patients and R1/2 in 3 (7\%) patients, 19 patients had lymph vascular space invasion (44.2\%) and 11patients (25.6\%) had perineural invasion. Skin invasion in $6(14 \%)$ patients, and $2(4.7 \%)$ patients, had regional nodal recurrence. Respectively in (Table 2).

In Compendium, $\mathrm{pN}+$ disease was found in 43 patients (100\%), comprising $3(7 \%)$ patients with pN1, and 40 (93\%) patients with pN2. respectively. Modified radical Neck dissection Ipsilateral $42(97.7 \%)$ patients, Bilateral $1(2.3 \%)$ patients, the median number of lymph nodes removed from the cervical neck was 29(range, 23-41 lymph nodes)., Pathologically positive lymph node 4 (range: 1-8 Nodes) LN percent positive14.3 (range: 3.03-28.57), respectively in (Table 3). 


\section{Cancer Therapy \& Oncology International Journal}

Table 2: Clinicopathologic characteristic of 43 patients with parotid gland tumors.

\begin{tabular}{|c|c|c|c|}
\hline & & Count & Column N \% \\
\hline \multirow{3}{*}{ T stage } & $\mathrm{T} 3$ & 26 & $60.5 \%$ \\
\hline & $\mathrm{T} 4$ & 17 & $39.5 \%$ \\
\hline & Total & 43 & $100.0 \%$ \\
\hline \multirow{3}{*}{ Cytological grade } & high-grade & 28 & $65.1 \%$ \\
\hline & intermediate/low & 15 & $34.9 \%$ \\
\hline & Total & 43 & $100.0 \%$ \\
\hline \multirow{3}{*}{ Pre-operative fine needle aspiration } & No & 7 & $16.3 \%$ \\
\hline & Yes & 36 & $83.7 \%$ \\
\hline & Total & 43 & $100.0 \%$ \\
\hline \multirow{2}{*}{ Postoperative radiotherapy } & Yes & 43 & $100.0 \%$ \\
\hline & Total & 43 & $100.0 \%$ \\
\hline \multirow{3}{*}{ Resection status } & R0 & 40 & $93.0 \%$ \\
\hline & $\mathrm{R} 1 / 2$ & 3 & $7.0 \%$ \\
\hline & Total & 43 & $100.0 \%$ \\
\hline \multirow{3}{*}{ Positive margins } & Yes & 3 & $7.0 \%$ \\
\hline & No & 40 & $93.0 \%$ \\
\hline & Total & 43 & $100.0 \%$ \\
\hline \multirow{3}{*}{ Lymphovascular invasion } & No & 24 & $55.8 \%$ \\
\hline & Yes & 19 & $44.2 \%$ \\
\hline & Total & 43 & $100.0 \%$ \\
\hline \multirow{3}{*}{ Perineural invasion } & No & 32 & $74.4 \%$ \\
\hline & Yes & 11 & $25.6 \%$ \\
\hline & Total & 43 & $100.0 \%$ \\
\hline \multirow{3}{*}{ Nodal recurrence } & No & 41 & $95.3 \%$ \\
\hline & Yes & 2 & $4.7 \%$ \\
\hline & Total & 43 & $100.0 \%$ \\
\hline \multirow{3}{*}{ Skin invasion } & No & 37 & $86.0 \%$ \\
\hline & Yes & 6 & $14.0 \%$ \\
\hline & Total & 43 & $100.0 \%$ \\
\hline
\end{tabular}

Table 3: Lymph nodes harvested and pathologically positive number.

\begin{tabular}{|c|c|c|c|c|c|}
\hline & Mean & Std. Deviation & Median & Minimum & Maximum \\
\hline Lymph nodes harvested & 30.1 & 4.5 & 29.0 & 23.0 \\
\hline Pathologically positive lymph node & 4.2 & 1.9 & 4.0 & 1.0 & 8.0 \\
\hline LN percent positive & 14.4 & 7.0 & 14.3 & 3.03 & 28.57 \\
\hline
\end{tabular}

Concerning, the ratio of metastases to particular levels, the most collective locations of metastases in level II was noted in $31 / 43(72.1 \%)$, Level III metastasis in $21 / 43(48.8 \%)$, level I in 18/43(41.9\%), level IV in 17/43(39.5\%), and level $\mathrm{V}$ in 8/43(18.6\%), (Diagram 1). Regarding histological type, mucoepidermoid carcinoma was the most common found in (27.9\%), followed by carcinoma ex-pleomorphic adenoma (14.6\%), adenoid cystic carcinoma (11.6\%), acinic cell carcinoma (9.3\%), squamous cell carcinoma (7\%) and salivary duct carcinoma (7.4\%), (Diagram 2). 


\section{Cancer Therapy \& Oncology International Journal}
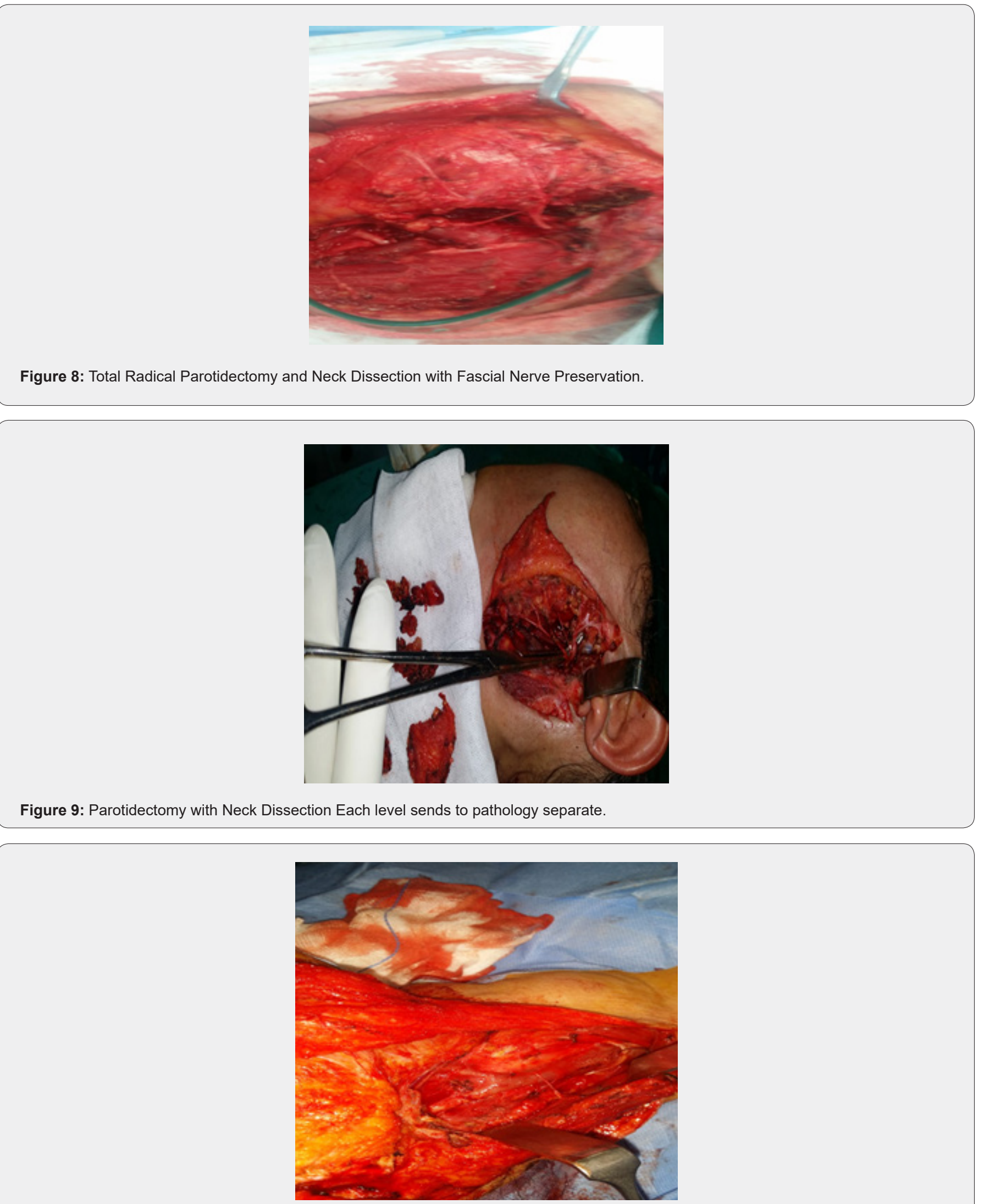

Figure 10: Ipsilateral Modified Neck Dissection for parotied Cancer. 


\section{Cancer Therapy \& Oncology International Journal}

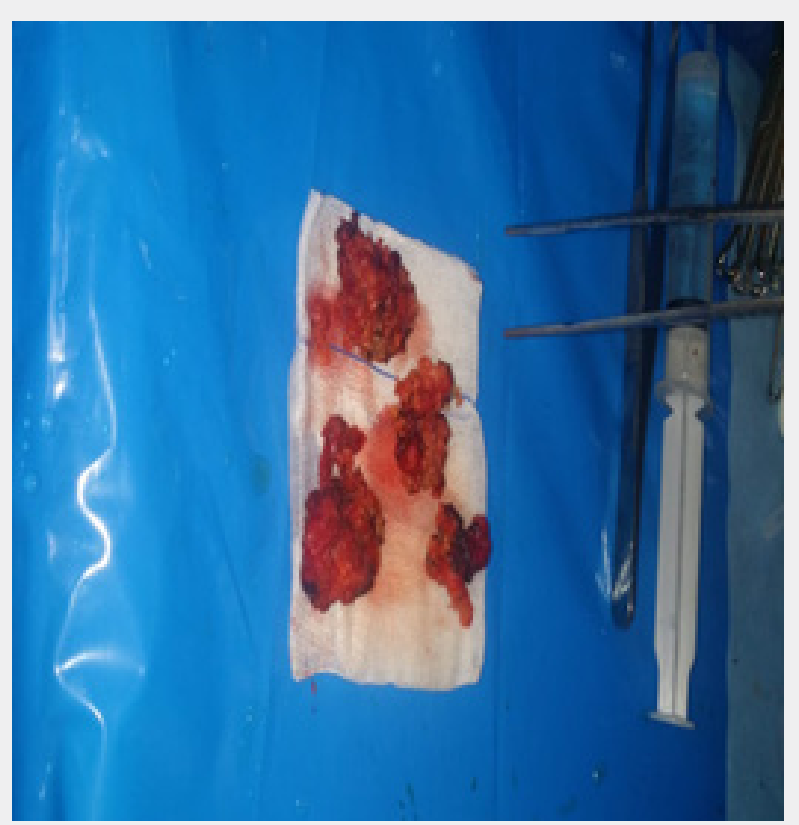

Figure 11: Modified Radical Neck Dissection After Parotied cancer Each level sent separate to pathology.

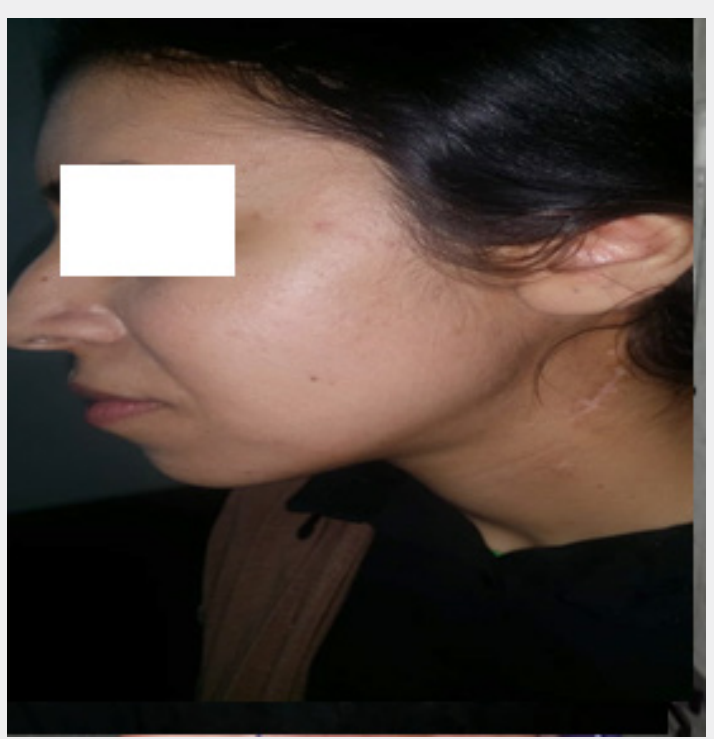

Figure 12: After 1 year Follow up after Left Total Radical Parotidectomy and Neck Dissection No visible scar.

\section{Discussion}

The incidence of cervical nodal disease in parotid carcinoma is reported to be around $14 \%$ to $16 \%$., High tumor grade, extra parotid extension, tumor size of $4 \mathrm{~cm}$ or more, pain, and facial nerve involvement are associated with nodal disease [5]. larger tumor size was related with a higher frequency of lymph node metastasis [11] Primary tumor size varied from $1.5 \mathrm{~cm}$ to $8 \mathrm{~cm}$ [5] Van der Poorten et al stated that facial nerve weakness or paralysis is present in up to $25 \%$ of patients, independently of $\mathrm{T}$ classification, [2] the rate of postoperative facial paralysis (24.3\%) [4] For nodal disease, predictors include histologic type, grade, presence of facial nerve dysfunction, tumor size $.5 \mathrm{~cm}$, age. 54 years, extra glandular spread, and per lymphatic spread [12] Bhattacharyya and Fried found that only tumors approaching sizes of $5 \mathrm{~cm}$ were independently predictive [12] While T4 was most predictive in our data, T2 and T3 remained significant predictors [12] higher $\mathrm{T}$ stage was independently a significant 
predictor of regional metastasis in multivariate analysis [12] (18.8\%) presented with facial nerve paresis or paralysis [13] Facial paresthesia or anesthesia and facial pain at presentation were found in $7.0 \%$ and $15.6 \%$ of patients, respectively [13]. tumors most commonly occupied the superficial lobe (86.9\%) [14] the frequency of facial palsy is 9-25\%, [15] Vincent et al. found that facial-nerve dysfunction, perineural growth and positive surgical margins acted as major factors predicting recurrence [16]. In our series, age 52 years, Primary tumor size varied $<4 \mathrm{~cm}$ in $(51.2 \%), \geq 4 \mathrm{~cm}$ in $(48.8 \%)$ patients, $\mathrm{T} 3(60.5 \%)$, and $\mathrm{T} 4(39.5 \%)$ patients, superficial lobe was infiltrate in (60.5\%) cases, extra parotid extension in $32.6 \%$, facial nerve involvement in $9.3 \%$ was comparable to that in prior reports.

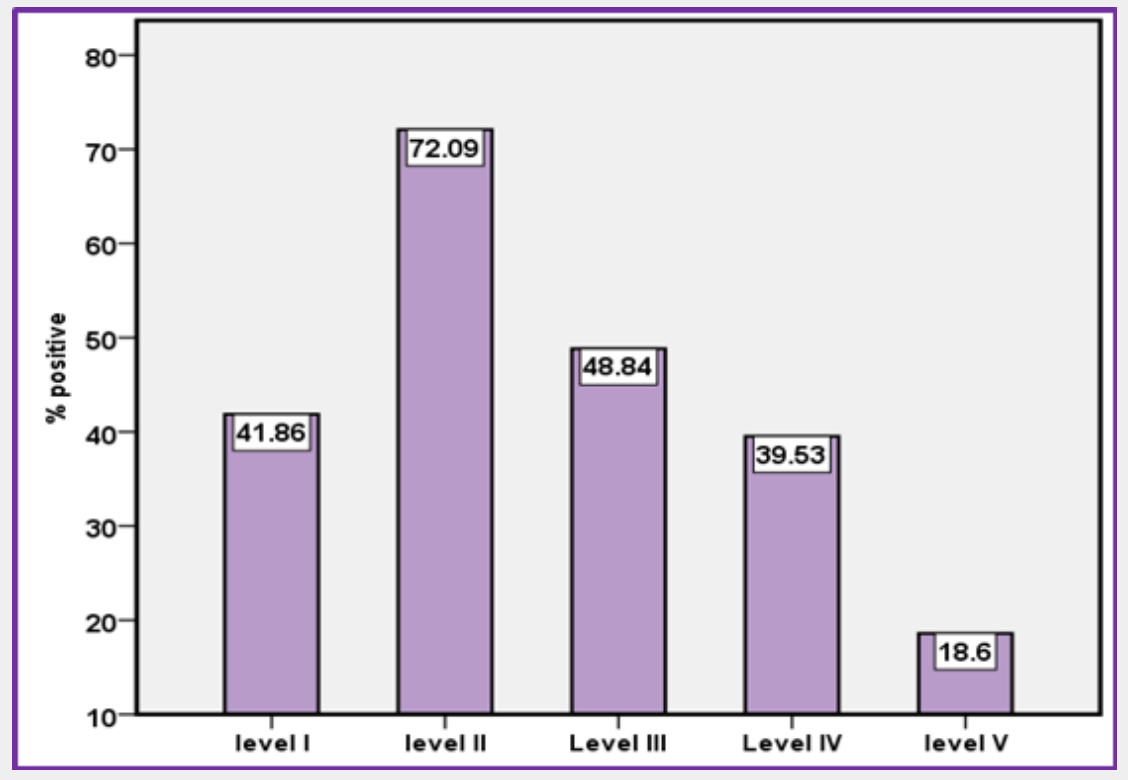

Diagram 1: The ratio of metastases to particular levels.

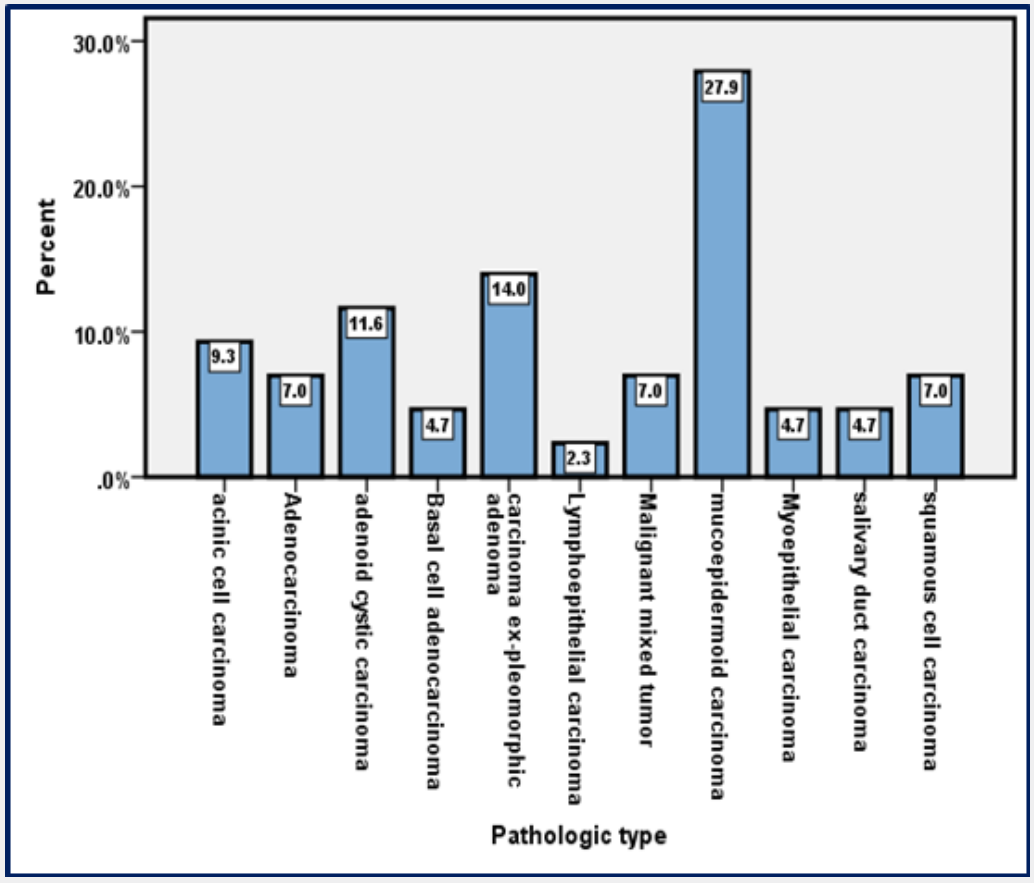

Figure 11: Modified Radical Neck Dissection After Parotied cancer Each level sent separate to pathology. 


\section{Cancer Therapy \& Oncology International Journal}

In this study, pain was noted in $52 \%$ of all parotid carcinoma patients. Pohar et al. reported that pain in 34\% patients, while Godballe et al. reported pain in $31 \%$ of parotid carcinoma patients and pain was a poor prognostic factor. While Stodulski et al. reported pain was present in $40 \%$ of parotid carcinoma patients; they also concluded that it was not a prognostic factor [15] pain may be the only prognostic symptom that is useful in the pretreatment diagnosis of parotid carcinoma [10] whereas localized pain in the parotid region tends to appear more often [2] Only $25-30 \%$ of parotid carcinomas showed clear clinical manifestation of malignancy [16]. In our study, pain in $27.9 \%$, was comparable to that in prior reports. It was reportedly that adhesion to the skin was found in $9 \%$ of patients and adhesion to deep tissues in 13-18\% [15]. In our study, Skin invasion in 14\% was comparable to that in prior reports a high rate of pathological positive nodes in levels II to IV, disease positivity in the neck was also more likely in level I and V (51.6 \& $40 \%$ ). Therefore, it would seem prudent to carry out a comprehensive neck dissection at levels I to $\mathrm{V}$ for all patients with a clinically disease-positive neck [17].

Regarding the extent of END, whilst a modified radical neck dissection of levels I-V is generally recommended in patients with parotid carcinoma and clinical evidence of nodal metastasis, there is currently a lack of consensus on which lymph node levels should be included in the END. This divergence found in our analysis of included studies, with some authors supporting an elective SND (levels I-III or II-III or I-III/Va) and others an elective RMND (levels I-V). However, overall, among the 8 studies reported data on the extent of END, the levels most often included in the dissection were I-II-III [18]. Klussmann et al. reported the most common site of metastasis was level II (75\%), Stodulski et al. found that metastasis was most common at level 2, followed by levels III and 5, 20\% by level V; [11] the overall distribution of cervical disease in primary parotid carcinoma is diffuse. Although level I is the least often involved, it still contains metastatic deposits in $28 \%$ cases. The wide distribution of nodal disease may be due, in part, to the area within the parotid that the carcinoma originated [5]. Ebrahimi et al. substantive the results of $126 \mathrm{cP}+\mathrm{N} 0$ neck dissections [5]. Level II was most commonly (35.6\%), level III (14.6\%); levels I, IV, and V in $11.2 \%$ of cases [19]. O'Brien et al. reported a case series of $37 \mathrm{cP}+\mathrm{N} 0$ necks, 13 (35.1\%) had occult disease. Of these, $61.5 \%$ had level II disease, $30.8 \%$ in level III disease, $23.1 \%$ in levels I or IV, and $7.7 \%$ in level V. [19] the most prevalent location of occult metastases was level II (70\%), I, III and $\mathrm{V}$ levels in $20 \%$. Involvement of level V( $3 / 6$ series $)$ most probably it is associated with location and local stage of the tumour [1]. In our study, reported a similar frequency of Ipsilateral Modified radical Neck dissection Ipsilateral $142(97.7 \%)$ patients. The most common locations in level II (72.1\%), Level III (48.8\%), level I in (41.9\%), level IV in (39.5\%), and level V in (18.6\%).

Recent studies have reported the accuracy rates of FNA for parotid masses ranging from $90 \%-95 \%$ [20]. Values of 62\%-79\% sensitivity and $98-100 \%$ specificity for diagnosis of malignant tumors were reported [21]. The accuracy of fine-needle aspiration ranges from $84 \%-97 \%$ in malignant tumors of the salivary gland [8] FNAC, with sensitivity $75 \%, 24,25$ has a relatively high risk of false results for malignant tumors [2] other reported, it is not possible to assess with $100 \%$ certainty the grade and histology of salivary gland tumour [1].

In our study, Pre-operative fine needle aspiration (83.7\%) patients. Armstrong et al, reported occult metastasis found in $38 \%$. Zbaren et al. found in $20 \%$ and Klussmann et al. found in $18 \%$ [15] Stennert et al, found $45 \%$ had occult nodal metastases [22], the frequency of occult metastasis is reported to range widely from 5 to $31 \%$. Armstrong et al. (38\%) had occult metastasis. Other found in 20 to $37 \%$ [11]. Occult metastases were found in $5-31 \%$ of patients with parotid carcinoma [11] other detected in $12-48 \%$ [17]. In our study, $79.1 \%$ of patients had clinical nodal disease and $20.9 \%$ Occult metastasis, 27 patients (90\%) had nodal metastasis and node-positive patients having a neck dissection had evidence of nodal metastasis on pathology (100\%) [23]. High grade significantly increased nodal disease incidence for all histopathology's [12]. Because histologically high-grade parotid carcinoma is generally associated with a high incidence of metastasis [11]. High grade was most predictive of nodal disease for mucoepidermoid carcinoma, [12] Roberto et al. reported patients with high-grade and stage tumours had the worst prognoses [16]. In our series, High-grade cancer noted in (65.1\%); intermediate / low-grade cancer in (34.9\%).

Perineural invasion (PNI) found to be very strongly correlated to worse overall and disease-free survival [13] (18\%) patients had lymphovascular space invasion and $16 \%$ had perineural invasion [24]. In our series $25.6 \%$ had perineural invasion. Patients with positive surgical margins had significantly increased rates of distant metastasis. The lungs were the most common site [14]. Positive margin status noted to be predictive of worse disease-free survival [13] a positive tumor margin was found in $64.7 \%$, with close margins $(<0.5 \mathrm{~cm})$ in $27.1 \%$ [25]. In our series, resection status (R) was Negative margins R0 were achieved in $(93 \%)$ patients and $\mathrm{R} 1 / 2$ in $(7 \%)$ patients had positive margins. Chen et al. found level II was the most common site of nodal recurrence, and histology while, Tstage was the most important prognostic indicators for neck recurrence [26], (8.7\%) experienced recurrence [4]. Locoregional recurrence frequently occured in PGC, with ranging from 15\%-33\% [4]. The locoregional recurrence rate (13.2\%) [4] five regional recurrences occurred. One patient had regional recurrence in initially positive nodal area. The most common sites of nodal recurrence were ipsilateral level II followed by level III [25], the other patient had regional recurrence at levels III and IV [25]. In our series, 4.7\% patients, had regional nodal recurrence. Ebrahimi et al opposed our results, reporting that having excised LNs $>20$ have a protective effect due to minimizing the occurrence on occult nodal metastasis [27]. A higher LNR and the LN involvement indicate tumor 
aggressiveness and may be a source of metastasis as given by the spectrum theory of tumor metastasis [27]. The median number of lymph nodes removed from the cervical neck was 13 (range, 8-50 lymph nodes) [24]. (17\%) had single nodes [5], A prognostic implication of as 22 dissected lymph nodes/, >20 dissected lymph nodes were previously described as minimizing the prohibition of resting occult metastases [9]. A total of eight pathologically positive lymph nodes were detected in 3 patients in the END group, [28]. In our series the median number of lymph nodes removed from the cervical neck was 29(range, 23-41 lymph nodes)., Pathologically positive lymph node 4 (range: 1-8 Nodes) and LN percent positive14.3 (range: 3.03-28.57).

Duplication in the neck independent of the parotid was discussed in 8 papers, including 779 therapeutic and ENDs, as well as 31 treated with primary radiotherapy, with a mean LRR rate of $7.5 \%$ between $0 \%-12.4 \%$ [19]. In our series (4.7\%) patients, had regional nodal recurrence. Digonnet et al, the most common histologic types (acinic cell carcinoma, and lowgrade mucoepidermoid), [2] Primary tumor histopathologic types and differentiation are important determinants of the biological behavior of PGC and vary according to tumor grade. Spiro et al., found mucoepidermoid carcinoma was the most frequent histologic type of PGC, followed by malignant mixed tumor. This confirmed by several studies [4]. the most common primary neoplasias were mucoepidermoid and adenoidecystic carcinomas [21,29]. In our series We found that mucoepidermoid carcinoma was the most common (27.9\%), followed by carcinoma ex-pleomorphic adenoma (14.6\%), adenoid cystic carcinoma (11.6\%), acinic cell carcinoma (9.3\%) and salivary duct carcinoma (7.4\%).

Decisions regarding the need for adjuvant radiotherapy (RT) depend on advanced T stage, bone invasion, PNI and positive lymph node. Elective nodal irradiation (ENI) recommended for high-risk patients [25]. Treatment of parotid carcinoma with clinically lymph node metastases consists of neck dissection and postoperative radiation. Postoperative locoregional radiotherapy for the pathological positive neck node significantly improved regional control. Chen et al., postoperative elective neck irradiation to patients with clinically No carcinomas of the salivary glands reduced the 10-year nodal relapse rate from 26\%-0\% [6].

Frankenthaler et al. recommend elective radiation for cN0 high-risk tumors, thus controlling for microscopic disease if nodal disease is later found on pathologic analysis., Herman et al. found that for high-grade salivary malignancies, patients undergoing operation and postoperative radiation likely don't benefit from planned neck dissection [12]. Armstrong et al. found the rate of recurrence of neck disease was $29 \%$ in patients with pN disease after END who did not receive PORT. Therefore, PORT is generally stand for the $\mathrm{pN}$ neck after END. Of more controversy is whether ENI for the cN0 neck has equivalent efficacy to END [16]. PORT is provided for the primary surgical bed, and nodal basins at risk are also included in the radiation field [17]. Safdieh et al. found adjuvant radiotherapy improved gross survival [29] postoperative radiation for patients with nodal metastases increased localregional control, from $40 \%$ in patients treated with surgery alone to $69 \%$ in patients treated with surgery plus radiation to the neck. Survival rates were $19 \%$ and $49 \%$, respectively [30]. In our series all patients had postoperative radiotherapy. This study had many limitations inherent in its retrospective design, including a limited numeral of cases and the heterogeneity of patient characteristics and histological types. Thus, further studies analyzing the specific features of this group of patients are required.

\section{Conclusion}

In patients with positive cervical lymph nodes in partied cancer, all levels of the neck are prone to metastatic disease, and thus Ipsilateral Modified neck dissection from level I to $\mathrm{V}$ is required. Radiotherapy of the neck after operative is recommended. but, the histologic tumor stage, proceeding T3-4 stage, lymphovascular invasion, a fixed mass, extra parotid extension, fasical nerve invasion were revealed as major prognostic agent for Neck metastasis.

\section{Declarations}

\section{Acknowledgment}

None to declare.

\section{Financial Disclosure}

None to declare.

\section{Conflict of Interest}

None to declare.

\section{Author Contributions}

Ali Zedan: manuscript idea, research, writing. Aieat Morsy: writing, editing. Osama Mustafa: review, editing. Marwa Hussien: revision, editing. Ebrahim Aboeleuien: revision, editing.

\section{Data Availability}

The authors declare that data supporting the findings of this study are available within the article.

\section{References}

1. Stodulski D, Mikaszewski B, Majewska H, Wiśniewski P, Stankiewicz C (2017) Probability and pattern of occult cervical lymph node metastases in primary parotid carcinoma. European Archives of OtoRhino-Laryngology 274(3): 1659-1664.

2. Mantsopoulos K, Velegrakis S, Iro H (2015) Unexpected detection of parotid gland malignancy during primary extracapsular dissection. Otolaryngology--Head and Neck Surgery 152(6): 1042-1047.

3. Abdelwanis A, Barman S (2019) Management of the neck in malignant parotid neoplasm. International Journal of Otorhinolaryngology and Head and Neck Surgery 5(1): 236. 


\section{Cancer Therapy \& Oncology International Journal}

4. Chang JW, Hong HJ, Ban MJ, Shin YS, Kim WS, et al. (2015) Prognostic factors and treatment outcomes of parotid gland cancer: a 10-year single-center experience. Otolaryngology-Head and Neck Surg 153(6): 981-989.

5. Chisholm EJ, Elmiyeh B, Dwivedi RC, Fisher C, Thway K, et al. (2011) Anatomic distribution of cervical lymph node spread in parotid carcinoma. Head \& neck 33(4): 513-515.

6. Kim YH, Chung WK, Jeong JU, Cho IJ, Yoon MS, et al. (2020) Evaluation of prognostic factors for the parotid cancer treated with surgery and postoperative radiotherapy. Clinical and experimental otorhinolaryngology 13(1): 69

7. Lim CM, Gilbert M, Johnson JT, Kim S (2015) Is level V neck dissection necessary in primary parotid cancer. The Laryngoscope 125(1): 118121

8. Rahbar R, Grimmer JF, Vargas SO, Robson CD, Mack JW, et al. (2006) Mucoepidermoid carcinoma of the parotid gland in children: a 10-year experience. Archives of Otolaryngology-Head \& Neck Surg 132(4) 375-380

9. Meyer MF, Kreppel M, Meinrath J, Grünewald I, Stenner M, et al. (2017) Prediction of outcome by lymph node ratio in patients with parotid gland cancer. Clinical Otolaryngology 42(1): 98-103.

10. Maruo T, Fujimoto Y, Yoshida K, Hiramatsu M, Suzuki A, et al. (2014) Effect of clinical symptoms on the indication for selective neck dissection for N0 carcinomas of the parotid gland. Oncology letters 8(1): 335-338.

11. Jinnin T, Kawata R, Higashino M, Nishikawa S, Terada T, Haginomori SI et al. (2019) Patterns of lymph node metastasis and the management of neck dissection for parotid carcinomas: a single-institute experience. Int J Clin Oncol 24(6):624-631.

12. Xiao CC, Zhan KY, White-Gilbertson SJ, Day TA (2016) Predictors of nodal metastasis in parotid malignancies: a national cancer data base study of 22,653 patients. Otolaryngology--Head and Neck Surgery 154(1): 121-130.

13. Huyett P, Duvvuri U, Ferris RL, Johnson JT, Schaitkin BM, et al. (2018) Perineural invasion in parotid gland malignancies. Otolaryngol Head Neck Surg 158(6): 1035-1041.

14. McHugh CH, Roberts DB, El-Naggar AK, Hanna EY, Garden AS, et al. (2012) Prognostic factors in mucoepidermoid carcinoma of the salivary glands. Cancer 118(16): 3928-3936.

15. Nishikado A, Kawata R, Haginomori SI, Terada T, Higashino M, et al (2018) A clinicopathological study of parotid carcinoma: 18-year review of 171 patients at a single institution. International journal of clinical oncology 23(4): 615-624.

16. Tao L, Zhang D, Zhang M, Zhou L (2019) Clinical behaviours and prognoses of high-and low-risk parotid malignancies based on histology. Eur Arch Otorhinolaryngol 276(2): 497-503.

17. Ali S, Palmer FL, DiLorenzo M, Shah JP, Patel SG, et al. (2014) Treatment of the neck in carcinoma of the parotid gland. Ann Surg Oncol 21(9): 3042-3048.
18. Borsetto D, Iocca O, De Virgilio A, Boscolo-Rizzo P, Phillips V, et al (2020) Elective neck dissection in primary parotid carcinomas: a systematic review and meta-analysis. J Oral Pathol Med.

19. Rotman A, Kerr SJ, Giddings CE (2019) Elective neck dissection in metastatic cutaneous squamous cell carcinoma to the parotid gland: A systematic review and meta-analysis. Head \& neck 41(4): 1131-1139.

20. Salgarelli AC, Capparè P, Bellini P, Collini M (2009) Usefulness of fineneedle aspiration in parotid diagnostics. Oral and maxillofacial surgery 13(4): 185-190.

21. Bohatch Júnior MS, Mendes RA, da-Silva AF, Lorenzini MS, Dohler AW, et al. (2018) Evaluation of postoperative complications in elderly patients undergoing parotidectomy. Review of the Brazilian College of Surgeons 45(4).

22. Valstar MH, van den Brekel MW, Smeele LE (2010) Interpretation of treatment outcome in the clinically node-negative neck in primary parotid carcinoma: a systematic review of the literature. Head \& neck 32(10): 1402-1411.

23. Walvekar RR, Filho PA, Seethala RR, Gooding WE, Heron DE, et al (2011) Clinicopathologic features as stronger prognostic factors than histology or grade in risk stratification of primary parotid malignancies. Head \& neck 33(2): 225-231.

24. Lau VH, Aouad R, Farwell DG, Donald PJ, Chen AM (2014) Patterns of nodal involvement for clinically N0 salivary gland carcinoma: refining the role of elective neck irradiation. Head \& neck 36(10): 1435-1439.

25. Huang BS, Chen WY, Hsieh CE, Lin CY, Lee LY, et al. (2016) Outcomes and prognostic factors for surgery followed by modern radiation therapy in parotid gland carcinomas. Japanese journal of clinical oncology 46(9): 832-838.

26. Wang YL, Li DS, Gan HL, Lu ZW, Li H, et al. (2012) Predictive index for lymph node management of major salivary gland cancer. The Laryngoscope 122(7): 1497-1506.

27. Elhusseiny KM, Abd-Elhay FA, Kamel MG, Abd El Hamid Hassan HH, E Tanany HH, et al. (2019) Examined and positive lymph nodes counts and lymph nodes ratio are associated with survival in major salivary gland cancer. Head \& neck 41(8): 2625-2635.

28. Szewczyk M, Golusiński P, Pazdrowski J, Pieńkowski P, Golusiński WJ (2019) Management of clinically negative neck in salivary gland cancers-elective neck dissection, irradiation, or surveillance. Contemporary Oncology 23(3): 169-173.

29. Niu X, Fang Q, Liu F (2019) Role of intraparotid node metastasis in mucoepidermoid carcinoma of the parotid gland. BMC cancer19(1): 417.

30. Papadogeorgakis N, Goutzanis L, Petsinis V, Alexandridis C (2012) Management of malignant parotid tumors. Oral and maxillofacial surgery 16(1): 29-34. 
This work is licensed under Creative Commons Attribution 4.0 License

DOI:10.19080/CTOIJ.2021.18.555977
Your next submission with Juniper Publishers will reach you the below assets

- Quality Editorial service

- Swift Peer Review

- Reprints availability

- E-prints Service

- Manuscript Podcast for convenient understanding

- Global attainment for your research

- Manuscript accessibility in different formats ( Pdf, E-pub, Full Text, Audio)

- Unceasing customer service

Track the below URL for one-step submission https://juniperpublishers.com/online-submission.php 